Correction

\title{
Correction: PreImplantation factor (PIF) protects cultured embryos against oxidative stress: relevance for recurrent pregnancy loss (RPL) therapy
}

Lindsay F. Goodale ${ }^{1,6}$, Soren Hayrabedyan², Krassimira Todorova ${ }^{2}$, Roumen Roussev $^{3}$, Sivakumar Ramu ${ }^{3,8}$, Christopher Stamatkin ${ }^{3,9}$, Carolyn B. Coulam ${ }^{3}$, Eytan R. Barnea ${ }^{4,5, *}$ and Robert 0 . Gilbert ${ }^{1,7, *}$

${ }^{1}$ Department of Clinical Sciences, College of Veterinary Medicine, Cornell University, Ithaca, NY, USA

${ }^{2}$ Institute of Biology and Immunology of Reproduction, Bulgarian Academy of Sciences, Sofia, Bulgaria

${ }^{3}$ CARI Reproductive Institute, Chicago, IL, USA

${ }^{4}$ BioIncept, LLC, Cherry Hill, NJ, USA

${ }^{5}$ Society for the Investigation of Early Pregnancy (SIEP), Cherry Hill, NJ, USA

${ }^{6}$ Department of Population Health and Reproduction, School of Veterinary Medicine, University of California-Davis, Davis, CA, USA

${ }^{7}$ Ross University School of Veterinary Medicine, Basseterre, St. Kitts, West Indies

8 Promigen Life Sciences, Downers Grove, IL, USA

${ }^{9}$ Therapeutic Validation Core, Indiana University Simon Cancer Center, Indiana University School of Medicine, Indianapolis, IN, USA

* These authors have contributed equally to this work

Published: December 18, 2018

Copyright: Goodale et al. This is an open-access article distributed under the terms of the Creative Commons Attribution License 3.0 (CC BY 3.0), which permits unrestricted use, distribution, and reproduction in any medium, provided the original author and source are credited.

This article has been corrected: The correct Author name is given below:

\section{Soren Hayrabedyan}

Original article: Oncotarget. 2017; 8:32419-32432. https://doi.org/10.18632/oncotarget.16028 